\title{
Larval settlement and metamorphosis in a marine gastropod in response to multiple conspecific cues
}

\author{
Abigail E. Cahill ${ }^{\text {Corresp., }}{ }^{1,2}$, Spencer A. Koury ${ }^{2}$ \\ ${ }^{1}$ Institut Méditerranéen de Biodiversité et d'Ecologie marine et continentale (IMBE), Aix Marseille Université, CNRS, IRD, Avignon Université, Marseille, \\ France \\ 2 Department of Ecology and Evolution, State University of New York at Stony Brook, Stony Brook, NY, United States \\ Corresponding Author: Abigail E. Cahill \\ Email address: abigail.cahill@imbe.fr
}

Larvae of the marine gastropod Crepidula fornicata must complete a transition from the plankton, where they are highly dispersed, to an aggregated group of benthic adults. Previous research has shown that selective settlement of larvae on conspecific adults is mediated by a water-borne chemical cue. However, variable experimental conditions have been used to study this cue, and standardization is needed in order to investigate factors that may have weak effects on settlement. In this study, we developed a time-course bioassay based on a full-factorial design with temporal blocking and statistical analysis of larval settlement rates in the lab. We tested this bioassay by examining settlement in the presence of an abiotic cue $(\mathrm{KCl})$, and biotic cues (water conditioned with adult conspecifics and conspecific pedal mucus). Results confirmed settlement in the presence of both $\mathrm{KCl}$ and adult-conditioned water, and discovered the induction of settlement by pedal mucus. This optimized, standardized bioassay will be used in future experiments to characterize the complex process of larval settlement in $C$. fornicata, particularly to measure components of potentially small effect. 
1 Larval settlement and metamorphosis in a marine gastropod in response to multiple

2 conspecific cues

3 Abigail E. Cahill ${ }^{1,2 *}$ and Spencer A. Koury ${ }^{1}$

$4{ }^{1}$ Department of Ecology and Evolution, Stony Brook University, Stony Brook, NY 11794-5245

$5 \quad U S A$

62 Present address:

7 Institut Méditerranéen de Biodiversité et d'Ecologie marine et continentale (IMBE)

8 Aix Marseille Université, CNRS, IRD, Avignon Université

9 Station Marine d'Endoume, Chemin de la Batterie des Lions, 13007 Marseille, France

10

$11 *$ Corresponding author:

12 Abigail E. Cahill

13 Station Marine d'Endoume

14 Chemin de la Batterie des Lions

1513007 Marseille, France

16 abigail.cahill@imbe.fr

$17+330686536892$

18

19 Email addresses: spencer.koury@stonybrook.edu, abigail.cahill@imbe.fr

20

21 


\section{Abstract}

23 Larvae of the marine gastropod Crepidula fornicata must complete a transition from the

24 plankton, where they are highly dispersed, to an aggregated group of benthic adults. Previous

25 research has shown that selective settlement of larvae on conspecific adults is mediated by a

26 water-borne chemical cue. However, variable experimental conditions have been used to study

27 this cue, and standardization is needed in order to investigate factors that may have weak effects

28 on settlement. In this study, we developed a time-course bioassay based on a full-factorial

29 design with temporal blocking and statistical analysis of larval settlement rates in the lab. We

30 tested this bioassay by examining settlement in the presence of an abiotic cue $(\mathrm{KCl})$, and biotic

31 cues (water conditioned with adult conspecifics and conspecific pedal mucus). Results

32 confirmed settlement in the presence of both $\mathrm{KCl}$ and adult-conditioned water, and discovered

33 the induction of settlement by pedal mucus. This optimized, standardized bioassay will be used

34 in future experiments to characterize the complex process of larval settlement in C. fornicata,

35 particularly to measure components of potentially small effect. 


\section{Introduction}

39 An important challenge in ecology is understanding how broadly-dispersed propagules locate sites where they will survive as adults. Many marine invertebrates with complex life cycles have vastly different distributions in their adult and larval stages. Planktonic larvae can disperse tens to hundreds of kilometers during their larval period, while the benthic adults are often sedentary and aggregated in spatially restricted habitats (Cowen \& Sponaugle, 2009). Many larvae exhibit selective settlement, where the planktonic-benthic transition is mediated by physiological responses of larvae to physical or chemical cues associated with suitable sites for adults (Krug $\&$ Manzi, 1999) or from the adults themselves (Zimmer-Faust \& Tamburri, 1994).

The terminology used to describe the process of transitioning from a larva to a juvenile is variable. Terms here are consistent with Pawlik (1992), where settlement refers to the entire process of transitioning from a planktonic larva to a benthic juvenile, while metamorphosis is used to indicate irreversible developmental changes that prevent a larva from returning to its previous planktonic lifestyle. Therefore, the developmental process of metamorphosis is contained within the ecological process of settlement. avoid inappropriate habitats, or delay metamorphosis until appropriate cues are sensed (Morello \& Yund, 2016; Pechenik \& Eyster, 1989; Thorson, 1950; Woodin, 1986). Environmental cues known to cause larval settlement are diverse and may be associated with biofilms (the gastropod Crepidula onyx, Zhao \& Qian, 2002), organisms that provide food or habitat (the hydroid Proboscidactyla flavicirrata, Donaldson, 1974; the soft coral Alcyonium siderium, Sebens, 1983), conspecifics (the barnacle Semibalanus balanoides, Gabbott \& Larman, 1987; the polychaete worm Phragmatopoma californica, Jensen \& Morse, 1984; the oyster Crassostrea 
61 virginica, Zimmer-Faust \& Tamburri, 1994), or avoidance of organisms with negative impacts

62 (the polychaete worm Pseudopolydora kempi, Woodin, 1985).

The larvae of the calyptraeid gastropod Crepidula fornicata (Linnaeus, 1758) have a

64 planktonic period of two to four weeks (Collin, 2003), which allows for long larval dispersal

65

66

67

distances. Within a single location larvae also have a wide spatial distribution, demonstrated by plankton tows of a single estuary that found larvae present in areas without adults (Rigal et al., 2010). In contrast, the sedentary adults are patchily distributed within intertidal and shallow subtidal habitats (Henry et al., 2010; Hoch \& Cahill, 2012). Within these habitats adults exhibit a clumped distribution due to their tendency to form large, semi-permanent mating groups called stacks (Collin, 1995). The presence of small juveniles aggregated on adults demonstrates recruitment to these stacks (McGee \& Targett, 1989; Cahill, 2015).

Selective settlement of $C$. fornicata larvae in response to cues has been studied in the field. Juveniles preferentially aggregate on adults and increased adult density increases larval recruitment (McGee \& Targett, 1989; Bohn et al., 2013a,b; Cahill, 2015), consistent with the idea of a cue associated with conspecific adults. Additional support for the role of settlement cues comes from laboratory studies. Larvae metamorphose in response to dissolved or suspended cues, including increased concentrations of potassium chloride $(\mathrm{KCl}$; Pechenik \& Heyman, 1987), dibromomethane from coralline algae (Taris et al., 2010), and seawater conditioned with conspecific adults (Pechenik \& Heyman, 1987; Pechenik \& Gee, 1993; Bohn et al., 2013b). This is also consistent with a conspecific waterborne cue, though the nature of the cue remains unknown. In some studies of settlement in C. fornicata, adult-conditioned seawater was prepared in the same vessel in which larvae were tested (Penniman et al., 2013), confounding the effect of the adult-conditioned water with any potential effect of pedal mucus 
84 produced by adult snails. Molluscan pedal mucus is known to affect settlement rates in other

85 marine invertebrate larvae such as barnacles (Johnson \& Strathmann, 1989; Holmes, 2002).

86 The existence of a conspecific waterborne cue that induces settlement in C. fornicata has

87 been supported using a variety of experimental designs and assay conditions (e.g. Pechenik \&

88 Heyman, 1987; Pechenik \& Gee, 1993; Bohn et al., 2013b), but the chemical nature and

89 biological mechanism of this cue remain unknown. Further characterization of the cue requires

90 repeatable assays that control for biological, technical, and statistical sources of variation in

91 measurements of the settlement process. Biological variability is due to larval age, genetic

92 differences among larvae, and differences among egg masses in survival, growth, and

93 development (Hilbish et al., 1999). Technical variability stems from protocols that differ in

94 biotic and abiotic conditions known to affect larval settlement, including the mass of adults used

95 to produce the cue or the density of larvae in a trial (Pechenik \& Heyman, 1987; Pechenik \&

96 Gee, 1993; Padilla et al., 2014). An additional, statistical source of variability is introduced by

97 analysis of settlement based on data collected at a single time point. Using this procedure, the

98 results are sensitive to the form of the mathematical function assumed for settlement rate and

99 dependent on which time point is selected (e.g. performing an ANOVA on the proportion of

100 larvae settled at a single timepoint assumes a constant rate of settlement through time).

101 Following the observation that $C$. fornicata distributions differ between the planktonic

102 larval and benthic adult life stages, and building on previous work with conspecific cues, we

103 aimed to provide a standard by which we can then investigate the mechanism responsible for this

104 ecological transition. We developed a bioassay using a fully factorial, randomized block design,

105 which accounted for biological variability. Technical variability was minimized by optimization

106 and control of biotic and abiotic experimental conditions. To address the problem of statistical 
107 variability, we introduced an analysis that estimated settlement rates as a single parameter by

108 fitting an exponential function using multiple observations from regular intervals. Measuring

109 settlement through time with rates also allows for differentiation among cues of different

110 induction strength and response times. This analysis improved the ability of experiments to

111 repeatably detect changes in settlement rates in the complex larval settlement system of $C$.

112 fornicata.

113

\section{Methods}

\section{Crepidula fornicata collection and husbandry}

116 We collected adult Crepidula fornicata from Crab Meadow Beach (Northport, New York, USA:

$\left.11740^{\circ} 55^{\prime} 46^{\prime \prime} \mathrm{N}, 73^{\circ} 19^{\prime} 38^{\prime \prime} \mathrm{W}\right)$ in July 2013 and returned them to the lab the same day. No permit is

118 required for collecting this species in New York State, and animals were not returned to the field.

119 Adult females were removed from their substrates to check for incubating egg capsules.

120 Capsules with larvae that were ready to hatch (stage IV veligers sensu Leroy et al., 2013) were

121 selected and hatched by physically agitating them in a bowl of filtered seawater at room

122 temperature. Larvae from three females were combined for rearing in cultures of $800 \mathrm{ml}$ of 1

$123 \mu \mathrm{m}$-filtered seawater (FSW) at a concentration of one larva per four ml. We collected seawater

124 from an underground well at Flax Pond Marine Laboratories, Old Field, New York, USA

$125\left(40^{\circ} 57^{\prime} 49^{\prime \prime} \mathrm{N}, 73^{\circ} 08^{\prime} 26^{\prime \prime} \mathrm{W}\right)$. We fed larvae 40,000 cells/ml of the alga Isochrysis galbana (clone

126 T-ISO) daily. We maintained larval cultures at $20^{\circ} \mathrm{C}$ and replaced $\mathrm{FSW}$ via reverse filtration

127 every three to four days. We tested for larval competence (ability to metamorphose) every two

128 days once the larvae developed shell brims (Pechenik, 1984) and were at least $750 \mu \mathrm{m}$ long

129 (Pechenik \& Heyman, 1987). Competence was tested by placing 12-24 larvae (1-2 larvae from 
130 each culture) in $20 \mathrm{mM} \mathrm{KCl}$ solution for 8 hours. It is not possible to work with a larval culture

131 that has reached $100 \%$ competence, because at this point many larvae have spontaneously

132 metamorphosed and are no longer available for experiments. We therefore started the

133 experiment within 24 hours of the larvae reaching $75 \%$ competence $(75 \%$ of larvae

134 metamorphosed in response to $\mathrm{KCl}$; Pechenik \& Heyman, 1987), which occurred 19 days post-

135 hatch.

136

\section{Preparation of test solutions}

138 We tested three factors for induction of larval settlement: seawater conditioned with conspecific

139 adults, conspecific pedal mucus, and $20 \mathrm{mM}$ elevated $\mathrm{KCl}$. Prior to the start of the experiment,

140 we acid-cleaned all glassware for ten minutes in $10 \%$ concentrated $\mathrm{HCl}$, rinsed them in deionized

141 water, and then autoclaved them.

142 To create adult-conditioned seawater (ACW), we placed $100 \mathrm{~g}$ of adult $C$. fornicata (shell

143 and wet tissue mass) and one liter of FSW into a beaker, then oxygenated the water for twelve

144 hours. Large epibionts (e.g. barnacles, macroalgae) were removed from the shells, but shells

145 were not otherwise treated. One liter of FSW without C. fornicata, to be used as a control, was

146 also oxygenated. After twelve hours, adults were removed and ACW and FSW were filtered to

$14740 \mu \mathrm{m}$ with a Nitex mesh filter. Temperature, dissolved oxygen, salinity, and $\mathrm{pH}$ were measured

148 at all preparation steps. The biotic and abiotic parameters for the bioassay (temperature, salinity,

149 trial length, mass of adults used for cue preparation, etc.) are listed in Table 1. These values

150 were chosen based on optimization studies for each parameter where settlement was measured

151 over a range of values. The optimal value was chosen based on settlement rates. When multiple 
152 values gave similar settlement rates, we made our choice based on logistical concerns (details in 153 Fig. A1).

154 We prepared pedal mucus treatments (replicates with pedal mucus left by adult snails;

$155 \mathrm{PMG})$ at the same time that $\mathrm{ACW}$ was prepared. Individual replicates of the experiment were 156 conducted in $60 \mathrm{ml}$ drinking glasses (shot glasses or shooters; hereafter "glasses"). For each

157 PMG replicate, a single small $(\sim 15 \mathrm{~mm})$ adult $C$. fornicata was added to all glasses for 12 hours

158 at the same time that the ACW was prepared. Glasses were filled with $35 \mathrm{ml} \mathrm{FSW}$ and covered

159 to prevent evaporation and snail escape. All snails began the $12 \mathrm{~h}$ period at the bottom of the 160 glass, and so even though some crawled above the water line during this period, they still left

161 mucus footprints in the glasses. During the ACW preparation, glasses not receiving the PMG

162 treatment had adults removed and were acid-cleaned and autoclaved to remove the mucus. To

163 prevent desiccation of the mucus, we did not remove adults from glasses receiving the PMG

164 treatment until immediately before the start of the experiment; these glasses were then drained 165 For $\mathrm{KCl}$ treatments, we prepared a concentrated solution of $200 \mathrm{mM} \mathrm{KCl}$ in distilled 166 water, which was stored until use in the experiments (following Pechenik and Heyman 1987).

\section{Bioassay}

169 Because larvae are expected to become more likely to metamorphose as they develop, we used a

170 randomized complete block design to account for larval age, using the start date of the

171 experiment as a blocking factor (i.e. blocks were run through time). All blocks used the same

172 batch of larvae and therefore larvae in the later blocks were older. All blocks were run within a

173 ten-day period. All three factors ( $\mathrm{ACW}, \mathrm{PMG}, \mathrm{KCl})$ had two levels (present or absent) and were

174 tested using a factorial design (eight possible treatments; Fig. 1). The treatment combination 
175 where all factors were absent corresponded to FSW and served as a negative control. Each

176 treatment combination had three replicate glasses for 24 replicates per block ( 72 replicates total).

177 Each glass in the bioassay contained $20 \mathrm{ml}$ of the test solution (Fig. 1). To make the KCl

178 treatments, we added $2 \mathrm{ml}$ of the concentrated $\mathrm{KCl}$ solution to the test solution of the replicate

179 (either FSW or ACW; Fig. 1) for a final $\mathrm{KCl}$ concentration of $20 \mathrm{mM}$ elevated above FSW. Ten

180 larvae were then individually pipetted into each glass. Larval growth and development in many

181 marine larvae, including C. fornicata, varies among cultures (rearing beakers). This variation

182 was accounted for by placing one larva from each rearing beaker (ten total beakers) into each

183 replicate glass. The same set of rearing beakers was used in all three blocks of the experiment.

184 Every 12 hours, we counted the number of larvae metamorphosed in each replicate, and

185 recorded any mortality. Metamorphosis was measured by the loss of the velar lobes, meaning

186 that it was an irreversible step in development. We removed metamorphosed juveniles and dead

187 larvae from the trial at each time point. To limit bacterial growth and the buildup of waste

188 products, after 24 hours we replaced the test solution in the glasses with clean glasses containing

189 new $\mathrm{ACW}, \mathrm{KCl}$, and PMG prepared as described above, and individually pipetted larvae into the

190 clean glasses. The total time of the experiment was 48 hours, which included five time points

191 and two different preparations of test solutions. Larvae were not fed during the experiment.

193 Data analysis

194 We conducted an analysis based on settlement rates rather than the proportions of larvae settled

195 at a fixed time point, since proportions are sensitive to the underlying mathematical function of

196 settlement rate and the timepoint selected for the analysis. We modeled larval settlement by 
197 predicting the proportion of larvae settled $(y)$ at each timepoint ( $t$, in hours) using the cumulative

198 distribution function for the single-parameter exponential model:

$199 y=1-e^{-\lambda t}$.

200 Given a constant probability of settlement, the waiting times for a single individual to

201 settle $\left(t_{i}\right)$ in a given treatment are exponentially distributed. Note that this model assumes that all

202 larvae in the experiment are developmentally capable of settling (competent), although trials

203 began when only $75 \%$ of larvae were competent; it was not possible to wait for $100 \%$

204 competence due to high rates of spontaneous settlement under these conditions (see above).

205 Incomplete competence will not affect the overall results if competence is equal in all treatments,

206 a reasonable assumption given our random assignment of larvae to treatments. The exponential

207 distribution is defined by the single parameter $\lambda$, which can be estimated as

$208 \hat{\lambda}=n / \sum_{i=1}^{n} t_{i}$.

209 However, because not all larvae settled during the first 48 hours, we calculated $\lambda$ incorporating

210 Type I censoring with the following equation:

$211 \hat{\lambda}=\frac{r}{\sum_{i=1}^{r} t_{i}+T(n-r)}$,

212 where $n$ is the total number of larvae tested and $r$ is the number of larvae that settle during the

213 bioassay. Thus, $(n-r)$ is the number of non-metamorphosed larvae at time $T$ which represents

214 the end of the bioassay (fixed at 48 hours for all experiments). By modeling larval settlement in

215 this way, the settlement rate for each replicate could be summarized with a single value $(\hat{\lambda})$ that

216 used time-course data and also accounted for Type I censoring.

217 To analyze the experimental data, we corrected the number of larvae tested $(n)$ for

218 mortality (average mortality per block $=2 \%$, or approximately five larvae; mortality was

219 consistent among treatments) and then calculated $\hat{\lambda}$ for each replicate. We used data from the 
220 first block of the experiment to calculate the correlation between the predicted number of larvae

221 settled for each replicate at each timepoint (based on $\lambda$ ) and the observed number of larvae

222 settled.

223 The full experiment was then analyzed using $\hat{\lambda}$ as a response variable in an analysis of

224 variance. Blocks were treated as random effects and experimental treatment factors (ACW,

$225 \mathrm{PMG}, \mathrm{KCl}$ ) were treated as fixed effects. The treatment where all factors were absent was

226 equivalent to FSW and served as a control (Fig. 1). Planned comparisons were conducted of

227 each factor against this control $\left(\mathrm{H}_{0}: \mathrm{KCl}=\mathrm{FSW}, \mathrm{ACW}=\mathrm{FSW}\right.$, and $\left.\mathrm{PMG}=\mathrm{FSW}\right)$. The

228 significance of planned comparisons was assessed using the $95 \%$ confidence intervals of the

229 mean difference between the treatments. Confidence intervals that did not overlap with zero

230 indicated a significant difference between the treatment and the control (Motulsky, 2010).

231 Finally, in order to compare our results using rates to results that would be obtained by

232 using proportions, we calculated an ANOVA on the arcsine-squareroot transformed proportions

233 of larvae settled at each timepoint in the analysis (five separate ANOVAs). Statistics were

234 conducted using JMPIN (Version 4.0.4, (C) SAS Institute 2001) and R 3.0.1 (R Core

235 Development Team, 2013).

236

237 Results

238 Modeling settlement rates

239 The proportion of larvae expected to settle over successive twelve-hour intervals was predicted

240 by modeling settlement with the rate parameter $\lambda$ from the exponential distribution. The fit of

241 the estimated values of $\lambda(\hat{\lambda})$ to the observed cumulative proportions of larvae settled is

242 illustrated with data from the first block of the experiment (Fig. 2). The correlation of predicted 
243 and observed values was high (overall $\mathrm{r}=0.930, \mathrm{p}<0.001)$ and consistent across treatments

244 (Fig. 2A). The slope of the best-fit line of predicted and observed data was less than one (slope

$245=0.810 \pm 0.030 \mathrm{SE}$ ), indicating that the model slightly underpredicted at most time points (Fig.

246 2B). Modeling settlement as the rate parameter $\lambda$ was a more informative statistical analysis than

247 using proportions of larvae settled at a given time. Performing the analysis on arcsine-

248 transformed proportions using ANOVAs yielded inconsistent results, such that the significance

249 of both main effects and interaction terms depended on the time point selected for the analysis

250 (Table 2, Table A1).

251

\section{Larval settlement rates}

253 All factors showed an increased settlement rate $(\lambda)$ relative to the filtered seawater (FSW) control 254 (Fig. 3,4). The linear model contained two statistically significant treatment effects $\left(\mathrm{KCl}, \mathrm{F}_{1,62}=\right.$ 255 19.43, $\mathrm{p}<0.001 ; \mathrm{KCl}^{*} \mathrm{ACW}, \mathrm{F}_{1,62}=14.57, \mathrm{p}<0.001 ;$ Table 3), with block effects through time 256 accounting for $24.6 \%$ of total variation. The strength of the artificial cue was likely responsible

257 for significant interaction effects $\left(\mathrm{KCl}^{*} \mathrm{ACW}\right.$, Table 3), as complete induction by $\mathrm{KCl}$ allowed 258 for no additional effect of the ACW treatment.

259 The mean settlement rates $(\lambda$, in units of $\ln$ (number larvae settled per hour)) for $\mathrm{KCl}$, 260 ACW, PMG, and FSW were 0.01796, 0.01218 0.007234, and 0.000715, respectively. The 95\%

261 confidence intervals of the difference in mean settlement rates between each treatment factor and 262 the FSW control did not overlap with zero (difference in $\lambda$ between $\mathrm{KCl}-\mathrm{FSW}=0.01075$ 263 0.02374; ACW - FSW $=0.005248-0.017572 ; \mathrm{PMG}-\mathrm{FSW}=0.002583-0.010456)$. This

264 indicates that all factors induced settlement in C. fornicata (Fig. 4). 


\section{Discussion}

267 This experiment confirmed larval settlement induction in Crepidula fornicata by $20 \mathrm{mM}$

268 elevated potassium chloride $(\mathrm{KCl})$ as well as adult-conditioned water $(\mathrm{ACW})$ and discovered the

269 inductive effect of pedal mucus (PMG) in the absence of ACW (Fig. 3,4). Induction of

270 settlement in $C$. fornicata by $\mathrm{KCl}$ and $\mathrm{ACW}$ has been previously reported (Pechenik \& Heyman,

271 1987; Pechenik \& Gee, 1993; Bohn et al. 2013b). We reproduced these previous results with

272 statistical significance, validating the time-course bioassay and analysis using the rate parameter $273 \lambda$.

274 Using $\lambda$ to measure settlement rather than proportions of larvae settled at a single

275 timepoint allowed for a consistent analysis. When using proportions, the significance of both

276 main effects and interactions varied depending on the timepoint selected (Table 2), making the

277 analysis less robust to variation in experimental duration. The use of $\lambda$ will be particularly

278 important when measuring potentially weak effects of induction, which induce settlement at a

279 slower rate. The experiment presented here does not allow for any characterization of the

280 chemical cues involved in this complex settlement system. However, the bioassay and analysis

281 now provide a standardized protocol and statistical analysis for the estimation of subtle

282 differences in settlement rates under various treatments.

283 Pedal mucus is a weak inducer of settlement which was not detectable using the

284 proportions of larvae settled at particular timepoints (Table 2, Table A1), but which we were able

285 to detect by analyzing settlement rates (Fig. 3,4). Previous work has shown that molluscan pedal

286 mucus affects settlement in other organisms (the barnacles Balanus glandula and Semibalanus

287 balanoides: Johnson \& Strathmann, 1989; Holmes, 2002). Additionally, a study of settlement in

288 C. fornicata used a combined treatment of adult-conditioned water and pedal mucus to induce 
289 settlement (Penniman et al., 2013). However, our study is the first to demonstrate the inductive

290 effect of mucus in the absence of adult-conditioned water.

291 There may be other weak inducers of settlement that can be detected with the analysis of

292 settlement rates. Bacteria and biofilms have often been implicated in larval settlement, including

293 in Crepidula species (C. onyx; Zhao \& Qian, 2002). To limit bacterial growth in the current

294 experiment, larvae were transferred into new water and glasses after 24 hours. There was no

295 accelerated settlement in time points immediately preceding transfers, indicating that any effect

296 of bacterial populations on settlement is overwhelmed by the signal of the conspecific cues in

297 ACW and PMG treatments. However, we did not test explicitly for the effect of biofilms and

298 bacteria, which have been shown to be a weaker effect than conspecific cue in C. onyx (Zhao \&

299 Qian, 2002). The bioassay can be used to test for this effect, as well as measuring its strength

300 relative to conspecific cues in C. fornicata.

301 The sensitivity of the bioassay and analysis also allows for the characterization of the

302 chemical cues involved in C. fornicata settlement. Many chemical inducers of settlement are

303 known from other gastropods, including carbohydrates (Alderia modesta, Krug and Manzi,

304 1999), metabolites (Phestilla sibogae, Hadfield and Pennington, 1990), volatile halogenated

305 organic compounds (Haliotis discus hannai, Kang et al., 2004), and peptides (Adalaria proxima,

306 Lambert et al., 1997). Work is currently underway to use the bioassay to begin to characterize

307 the cue present in both ACW and PMG (A. Cahill and S. Koury, unpublished data).

308 The optimization and standardization of the conditions of the bioassay allowed us to

309 account for several sources of variation in larval settlement. Settlement rates in this study were

310 variable among temporal blocks, with nearly one quarter of the variation in settlement rate

311 explained by block effects. Larval settlement rate is expected to change through time as larvae 
312 become competent during development. The use of a blocked design allowed us to statistically

313 account for this variation while increasing our sample size beyond the number of larvae that

314 could be tested at one time.

315 Differences in competency among larvae within a block could be explained by

316 differences in larval growth rate (Pechenik \& Lima, 1984; Pechenik et al., 1996) due to food

317 availability or temperature (Padilla et al., 2014). However, we controlled variation by rearing all

318 larvae on the same diet and at the same temperature. Variation in larval growth rate of $C$.

319 fornicata is also influenced by sire (Le Cam et al., 2009) and maternal effects (Hilbish et al.,

320 1999). Another potential source of variation among broods was due to the fact that we

321 artificially hatched the larvae, rather than waiting for natural hatching. We attempted to control

322 for this by only hatching very late-stage embryos, but some broods may have been more

323 developmentally advanced than others, leading to higher settlement rates. Due to the size of the

324 experiment and logistical constraints, we were unable to statistically account for these effects

325 (i.e. by blocking according to brood). By randomly mixing larvae from multiple broods, we

326 spread unknown brood-related variation evenly among all treatments and blocks, so such

327 variation does not impact our overall results regarding the different treatments.

328 Variation in settlement rate among larvae may also explain the discrepancy between the

329 fact that $75 \%$ of the larvae tested in $\mathrm{KCl}$ were competent before an experiment began, but that

330 settlement was consistently lower than $75 \%$ in the $\mathrm{KCl}$ treatments under experimental conditions

331 (Fig. 3, Fig. A1e). The $\mathrm{KCl}$ used for the competency tests was prepared in the same way as that

332 for the experiment itself. Although the use of $\mathrm{KCl}$ solution prepared in DI water reduced the

333 salinity to approximately 26 , slightly below values reported as optimal in Table 1 , these

334 treatments nonetheless showed high levels of settlement, and larval behavior did not appear 
335 impacted. The salinity levels remained near or above the values observed at the collection site in

336 Northport (e.g. salinity in June 2015 was 24.1; A. Cahill, unpublished data).

337 In addition to variation among larvae, there was variation among preparations of both the

338 ACW and the PMG: different adult animals were used for each preparation. The standardization

339 of the abiotic and biotic parameters of the experiment minimized differences among blocks

340 associated with preparation of adult-conditioned water (Table 1, Fig. A1). However, in the

341 absence of a clearly identified chemical that induces settlement, it remains impossible to control

342 the exact concentration of cue delivered to the larvae.

343 Food limitation has also been shown to increase settlement rates in C. fornicata

344 (Pechenik et al., 1996). This may have played a role in our experiment, since larvae were not fed

345 during the settlement trials. This food limitation was the same across treatments, and does not

346 explain the high settlement rates in $\mathrm{KCl}$ and $\mathrm{ACW}$ treatments relative to $\mathrm{FSW}$. It may, however,

347 explain the small number of larvae that settled in the FSW treatment despite the absence of

348 settlement cues (Fig. 3,4). This spontaneous, background settlement potentially due to food

349 limitation should be the same across treatments.

350

351 Conclusion

352 We developed an optimized time-course bioassay to estimate larval settlement rates in $C$.

353 fornicata. We replicated previous results by demonstrating settlement in response to both

354 elevated concentrations of $\mathrm{KCl}$ and a waterborne conspecific cue. For the first time, we

355 demonstrated that pedal mucus from adult conspecifics induces settlement in the absence of

356 adult-conditioned water. Future work using our new bioassay will characterize these cues and

357 investigate other potentially weak inducers of settlement. 


\section{Acknowledgements}

360 W. Bruno, A. Pellman-Isaacs, and J. Tay helped with larval rearing. We thank J. Levinton and

361 W. Eanes for lab space and equipment, J. Rohlf for statistical advice, and J. Levinton, D. Padilla,

362 D. Futuyma, F. Viard, W. Eanes, J. Rollins, E. Rollinson, and several anonymous reviewers for

363 comments on previous versions of the manuscript.

\section{References}

366 Bohn K, Richardson CA, Jenkins SR. 2013a. The importance of larval supply, larval habitat selection and post-settlement mortality in determining intertidal adult abundance of the invasive gastropod Crepidula fornicata. Journal of Experimental Marine Biology and Ecology, 440: 132-140. DOI:10.1016/j.jembe.2012.12.008.

Bohn K, Richardson CA, Jenkins SR. 2013b. Larval microhabitat associations of the non-native gastropod Crepidula fornicata and effects on recruitment success in the intertidal zone. Journal of Marine Biology and Ecology, 448: 289-297. DOI:10.1016/j.jembe.2013.07.020.

374 Cahill AE. 2015. Adult density affects larval recruitment in the calyptraeid gastropod Crepidula fornicata. Journal of Experimental Marine Biology and Ecology, 465: 77-82. DOI:10.1016/j.jembe.2015.01.013.

Collin R. 1995. Sex, size, and position: a test of models predicting size at sex change in the protandrous gastropod Crepidula fornicata. American Naturalist, 146: 815-831. Ecology Progress Series, 247: 103-122. 
381 Cowen RK, Sponaugle S. 2009. Larval dispersal and marine population connectivity. Annual 382 Reviews of Marine Science, 1: 443-466. DOI: 10.1146/annurev.marine.010908.163757.

383 Donaldson S. 1974. Larval settlement of a symbiotic hydroid: specificity and nematocyst responses in planulae of Proboscidactyla flavicirrata. Biological Bulletin, 147: 573-585.

385 Southward AJ, ed. Barnacle Biology. Rotterdam: A.A. Balkema, 377-388.

Hadfield MG, Pennington JT. 1990. Nature of the metamorphic signal and its internal transduction in larvae of the nudibranch Phestilla sibogae. Bulletin of Marine Science, 46: 455-464.

Henry JJ, Collin R, Perry KJ. 2010. The slipper snail, Crepidula: an emerging lophotrochozoan model system. Biological Bulletin, 218: 211-229.

Hilbish TJ, Sasada K, Eyster LS, Pechenik JA. 1999. Relationship between rates of swimming and growth in veliger larvae: genetic variance and covariance. Journal of Experimental Marine Biology and Ecology, 239: 183-193. DOI:10.1016/S0022-0981(99)00009-X.

Hoch JM, Cahill AE. 2012. Variation in size at sex-change among natural populations of the protandrous hermaphrodite, Crepidula fornicata (Gastropoda, Calyptraeidae). Marine Biology, 159: 897-905. DOI:10.1007/s00227-011-1867-4.

Holmes SP. 2002. The effect of pedal mucus on barnacle cyprid settlement: a source for indirect interactions in the rocky intertidal? Journal of the Marine Biological Association of the United Kingdom, 82: 117-129. DOI: http://dx.doi.org/10.1017/S0025315402005234.

Jensen RA, Morse DE. 1984. Intraspecific facilitation of larval recruitment: gregarious settlement of the polychaete Phragmatopoma californica (Fewkes). Journal of 
403

404

405

406

407

408

409

410

411

412

413

414

415

416

417

418

419

420

421

422

423

424

425

Experimental Marine Biology and Ecology, 83: 107-126. DOI:10.1016/00220981(84)90040-6.

Johnson LE, Strathmann RR. 1989. Settling barnacle larvae avoid substrata previously occupied by a mobile predator. Journal of Experimental Marine Biology and Ecology, 128: 87103. DOI:10.1016/0022-0981(89)90094-4.

Kang KH, Kim BH, Kim J M. 2004. Induction of larval settlement and metamorphosis of the abalone, Haliotis discus hannai larvae using bromomethane and potassium chloride. Aquaculture, 230: 249-259. DOI:10.1016/S0044-8486(03)00440-X.

Krug PJ, Manzi AE. 1999. Waterborne and surface-associated carbohydrates as settlement cues for larvae of the specialist marine herbivore Alderia modesta. Biological Bulletin, 197: 94-103.

Lambert WJ, Todd CD, Hardege JD. 1997. Partial characterization and biological activity of a metamorphic inducer of the dorid nudibranch Adalaria proxima (Gastropoda: Nudibrancha). Invertebrate Biology, 116: 71-81. DOI: 10.2307/3226971.

Le Cam S, Pechenik JA, Cagnon M, Viard F. 2009. Fast versus slow larval growth in an invasive marine mollusc: does paternity matter? Journal of Heredity, 100: 455-464. DOI: 10.1093/jhered/esp007.

Leroy F, Meziane T, Riera P, Comtet T. 2013. Seasonal variation in maternal provisioning of Crepidula fornicata (Gastropoda): fatty acid composition of females, embryos, and larvae. PLoS ONE, 8: e75316. DOI: 10.1371/journal.pone.0075316

McGee BL, Targett NM. 1989. Larval habitat selection in Crepidula (L.) and its effect on adult distribution patterns. Journal of Experimental Marine Biology and Ecology, 131: 195214. DOI:10.1016/0022-0981(89)90112-3. 
426 Morello SL, Yund PO. 2016. Response of competent blue mussel (Mytilus edulis) larvae to 427 positive and negative settlement cues. Journal of Experimental Marine Biology and 428 Ecology, 480: 8-16. DOI: 10.1016/j.jembe.2016.03.019.

429 Motulsky H. 2010. Intuitive Biostatistics, $2^{\text {nd }}$ ed. New York: Oxford University Press.

430 Padilla DK, McCann MJ, McCarty-Glenn M, Hooks AP, Shumway SE. 2014. Effect of food on 431 metamorphic competence in the model system Crepidula fornicata. Biological Bulletin, 432 227: $242-251$.

433 Pawlik JR. 1992. Chemical ecology of the settlement of benthic marine invertebrates.

434 Oceanography and Marine Biology, an Annual Review, 30: 273-335.

435 Pechenik JA. 1984. The relationship between temperature, growth rate, and duration of 436 planktonic life for larvae of the gastropod Crepidula fornicata (L.). Journal of Experimental Marine Biology and Ecology, 74: 241-257. DOI:10.1016/00220981(84)90128-X.

Pechenik JA, Eyster LS. 1989. Influence of delayed metamorphosis on the growth and metabolism of young Crepidula fornicata (Gastropoda) juveniles. Biological Bulletin, 176: 14-24.

442 Pechenik JA, Gee CC. 1993. Onset of metamorphic competence in larvae of the gastropod Crepidula fornicata, judged by a natural and an artificial cue. Journal of Experimental Marine Biology and Ecology, 167: 59-72. DOI:10.1016/0022-0981(93)90184-P.

445 Pechenik JA, Heyman WD. 1987. Using $\mathrm{KCl}$ to determine size at competence for larvae of the marine gastropod Crepidula fornicata (L.).Journal of Experimental Marine Biology and Ecology, 112: 27-38. DOI:10.1016/S0022-0981(87)80012-6 
448 Pechenik JA, Lima GM. 1984. Relationship between growth, differentiation, and length of larval

449 life for individually reared larvae of the marine gastropod, Crepidula fornicata.

$450 \quad$ Biological Bulletin, 166: 537-549.

451 Pechenik JA, Estrella MS, Hammer K. 1996. Food limitation stimulates metamorphosis of 452 competent larvae and alters postmetamorphic growth rate in the marine prosobranch 453 gastropod Crepidula fornicata. Marine Biology, 127: 267-275. DOI: 10.1007/BF00942112.

455 456

460

461

462

463

464

465

466

467

468

469 gastropod, Crepidula fornicata. Invertebrate Biology, 132: 14-26. DOI:

Penniman JR, Doall MK, Pires A. 2013. Neural correlates of settlement in veliger larvae of the 10.1111/ivb.12014.

R Core Team. 2013. R: A language and environment for statistical computing. R Foundation for Statistical Computing, Vienna, Austria. ISBN 3-900051-07-0, URL http://www.Rproject.org/

Rigal F, Viard F, Ayata S-D, Comtet T. 2010. Does larval supply explain the low proliferation of the invasive gastropod Crepidula fornicata in a tidal estuary? Biological Invasions, 12: 3171-3186. DOI : 10.1007/s10530-010-9708-9

Sebens K P. 1983. Settlement and metamorphosis of a temperate soft-coral larva (Alcyonium siderium Verrill): induction by crustose algae. Biological Bulletin, 165: 286-304.

Taris N, Comtet T, Stolba R, Lasbleiz R, Pechenik JA, Viard F. 2010. Experimental induction of larval metamorphosis by a naturally-produced halogenated compound (dibromomethane) in the invasive mollusc Crepidula fornicata (L.). Journal of Experimental Marine Biology and Ecology, 393: 71-77. DOI:10.1016/j.jembe.2010.07.001. 
470 Thorson G. 1950. Reproductive and larval ecology of marine benthic invertebrates. Biological $471 \quad$ Reviews of the Cambridge Philosophical Society, 25: 1-45.

472 Woodin SA. 1985. Effects of defecation by arenicolid polychaete adults on spionid polychaete 473 juveniles in field experiments: Selective settlement or differential mortality? Journal of $474 \quad$ Experimental Marine Biology and Ecology, 87: 119-132. DOI:10.1016/0022$475 \quad$ 0981(85)90085-1.

476 Woodin SA. 1986. Settlement of infauna: larval choice? Bulletin of Marine Science, 39: 401$477 \quad 407$.

478 Zhao B, Qian P-Y. 2002. Larval settlement and metamorphosis in the slipper limpet Crepidula 479 onyx (Sowerby) in response to conspecific cues and the cues from biofilm. Journal of $480 \quad$ Experimental Marine Biology and Ecology, 269: 39-51. DOI:10.1016/S0022-

481 0981(01)00391-4.

482 Zimmer-Faust RK, Tamburri MN. 1994. Chemical identity and ecological implications of a 483 waterborne, larval settlement cue. Limnology and Oceanography, 39: 1075-1087. DOI: 10.4319/lo.1994.39.5.1075. 
485 Table 1: Optimized values of abiotic and biotic parameters in the bioassay. Further details about

486 the optimization process can be found in Fig. A1.

\begin{tabular}{lll} 
Variable & Range Tested & Optimal Value \\
\hline $\mathrm{pH}$ & $7.9-10.2$ & $8.0-8.3$ \\
Salinity & $25-40$ & $27-30$ \\
Adult mass used for ACW & $4 \mathrm{~g}-800 \mathrm{~g}$ & $100 \mathrm{~g}$ \\
ACW preparation time & $1 \mathrm{~h}-24 \mathrm{~h}$ & $12 \mathrm{~h}$ \\
& & 10 \\
Larvae per replicate 20 ml glass & $5-20$ & $48 \mathrm{~h}$ \\
Trial length & $8 \mathrm{~h}-212 \mathrm{~h}$ & $12 \mathrm{~h}$ \\
& $4 \mathrm{~h}-24 \mathrm{~h}$
\end{tabular}

487

488 
489 Table 2: Heat map illustrating the change in significance through time of main effects and 490 interactions tested, analyzed using ANOVAs on arcsine square root transformed proportions;

491 calculations were done at each time step. Values in cells represent p-values for each factor at 492 each timestep. Dark grey: $p<0.001$; light grey: $0.001<p<0.05$; white: $p>0.05$. Full 493 ANOVA tables for each timestep can be found in Table A1.

\begin{tabular}{|c|c|c|c|c|}
\hline Source of Variation & 12 hours & 24 hours & 36 hours & 48 hours \\
\hline Adult Conditioned Water (ACW) & 0.408 & 0.301 & 0.002 & 0.006 \\
\hline Pedal Mucus Glass (PMG) & 0.936 & 0.949 & 0.0514 & 0.058 \\
\hline Potassium Chloride $(\mathrm{KCl})$ & $<0.001$ & $<0.001$ & $<0.001$ & $<0.001$ \\
\hline $\mathrm{PMG}^{*} \mathrm{ACW}$ & 0.750 & 0.223 & 0.046 & 0.026 \\
\hline $\mathrm{PMG}^{*} \mathrm{KCl}$ & 0.317 & 0.598 & 0.006 & 0.004 \\
\hline $\mathrm{ACW}^{*} \mathrm{KCl}$ & $<0.001$ & $<0.001$ & $<0.001$ & $<0.001$ \\
\hline $\mathrm{ACW} * \mathrm{PMG}^{*} \mathrm{KCl}$ & 0.207 & 0.182 & 0.145 & 0.096 \\
\hline
\end{tabular}

494 
496 Table 3: Analysis of variance table, conducted using rates $(\lambda)$ as the response variable.

497 Significant effects at $\mathrm{p}=0.05$ are highlighted in bold.

\begin{tabular}{lccccc}
\hline Source of Variation & df & SS & MS & F & $p$ \\
\hline Block Effect (Time of experiment) & 2 & $1.74 \mathrm{E}-03$ & $8.71 \mathrm{E}-04$ & ----- & ----- \\
Adult Conditioned Water (ACW) & 1 & $6.71 \mathrm{E}-05$ & $6.71 \mathrm{E}-05$ & 1.29 & 0.26 \\
Pedal Mucus Glass (PMG) & 1 & $1.26 \mathrm{E}-05$ & $1.26 \mathrm{E}-05$ & 0.24 & 0.63 \\
Potassium Chloride (KCl) & $\mathbf{1}$ & $\mathbf{1 . 0 1 E - 0 3}$ & $\mathbf{1 . 0 1 E - 0 3}$ & $\mathbf{1 9 . 4 3}$ & $<\mathbf{0 . 0 0 1}$ \\
PMG*ACW & 1 & $1.07 \mathrm{E}-04$ & $1.07 \mathrm{E}-04$ & 2.04 & 0.16 \\
PMG*KCl & 1 & $1.26 \mathrm{E}-04$ & $1.26 \mathrm{E}-04$ & 2.43 & 0.12 \\
ACW*KCl & $\mathbf{1}$ & $\mathbf{7 . 5 9 E - 0 4}$ & $\mathbf{7 . 5 9 E - 0 4}$ & $\mathbf{1 4 . 5 7}$ & $<\mathbf{0 . 0 0 1}$ \\
PMG*ACW*KCl & 1 & $6.51 \mathrm{E}-06$ & $6.51 \mathrm{E}-06$ & 0.12 & 0.72 \\
Error & 62 & $3.23 \mathrm{E}-03$ & $5.21 \mathrm{E}-05$ & 0.00 & \\
\hline Total & 71 & $7.06 \mathrm{E}-03$ & & & \\
\hline
\end{tabular}

498

499

500

501 
502

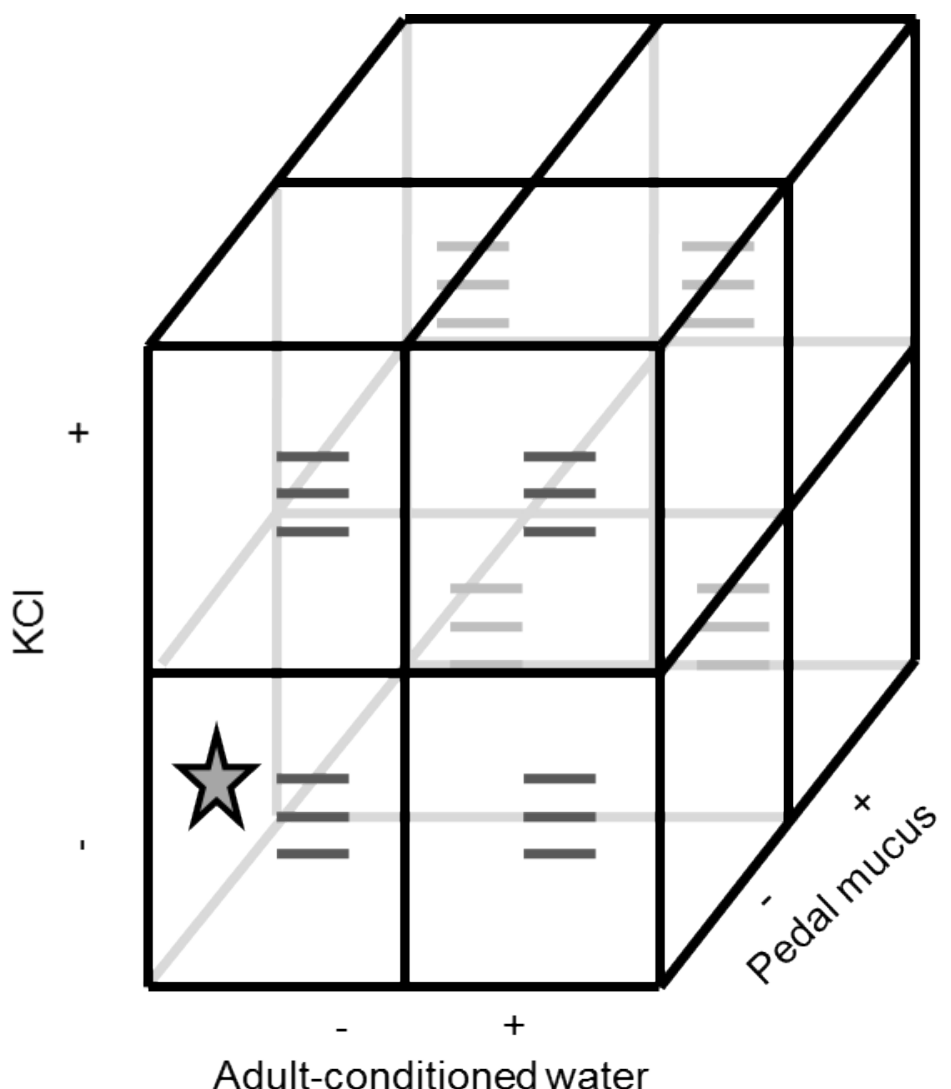

503

504 Figure 1: Experimental design. The experiment contained three factors (potassium chloride, adult-conditioned water, and pedal mucus), each either present $(+)$ or absent $(-)$, crossed in a factorial design for a total of eight treatments. Each treatment had three replicates (grey lines) with ten larvae in each replicate. The star indicates the treatment where all factors were absent. This treatment was equivalent to filtered seawater and served as the control. This design was repeated in three blocks through time (see details in text). 

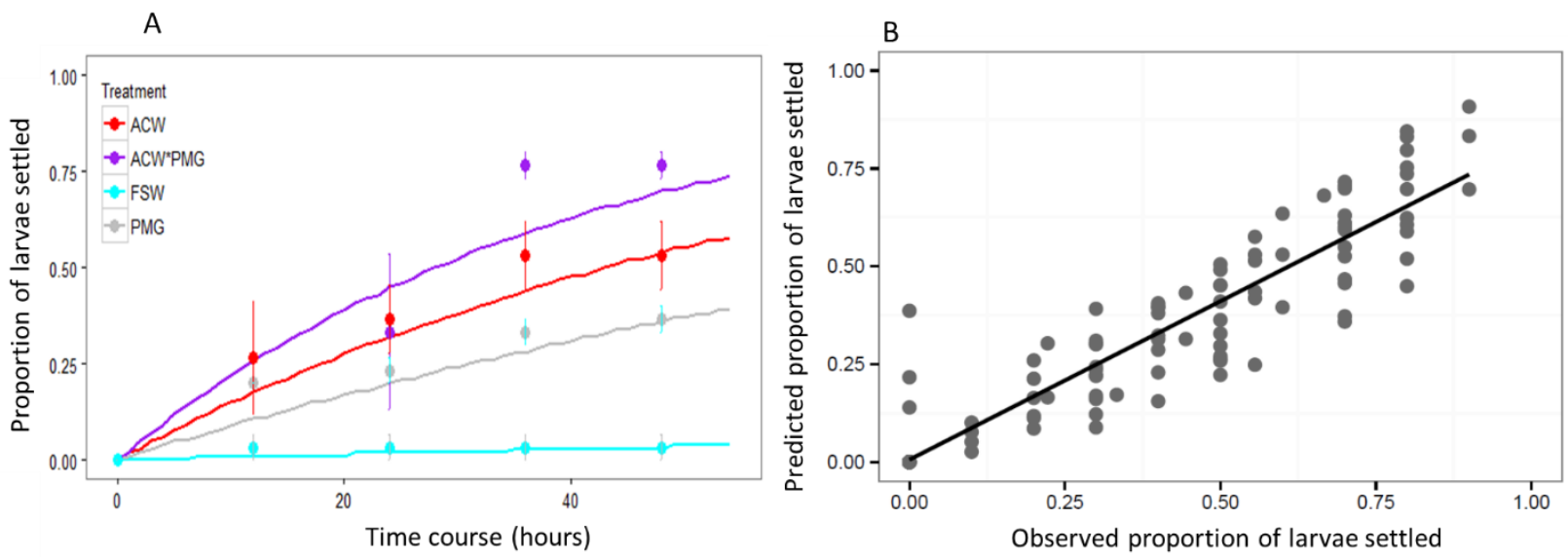

512 Figure 2: Fit of $\boldsymbol{\lambda}$ to observed data. A) Observed larval settlement (circles) and the values

513 predicted by $\lambda$ (lines) at each time point, plotted as the proportion of larvae settled at each point.

514 Values calculated based on the first block of the experiment. Error bars represent standard error.

515 There are close correlations between observed and expected values for all treatments: adult-

516 conditioned water $(\mathrm{ACW} ; \mathrm{r}=0.977, \mathrm{p}<0.001)$, adult-conditioned water and pedal mucus

$517(\mathrm{ACW} * \mathrm{PMG} ; \mathrm{r}=0.957, \mathrm{p}<0.001)$, pedal mucus glasses $(\mathrm{PMG} ; \mathrm{r}=0.965, \mathrm{p}<0.001)$, and

518 filtered seawater $(\mathrm{FSW} ; \mathrm{r}=0.710, \mathrm{p}<0.001)$. B) Plot of observed versus predicted proportions

519 of larvae settled in each glass at all time points. Values calculated based on the first block of the

520 experiment. The best-fit line is the linear regression to the data $(y=0.810 x+0.006 ; r=0.930 ; p$

$521<0.001)$ 


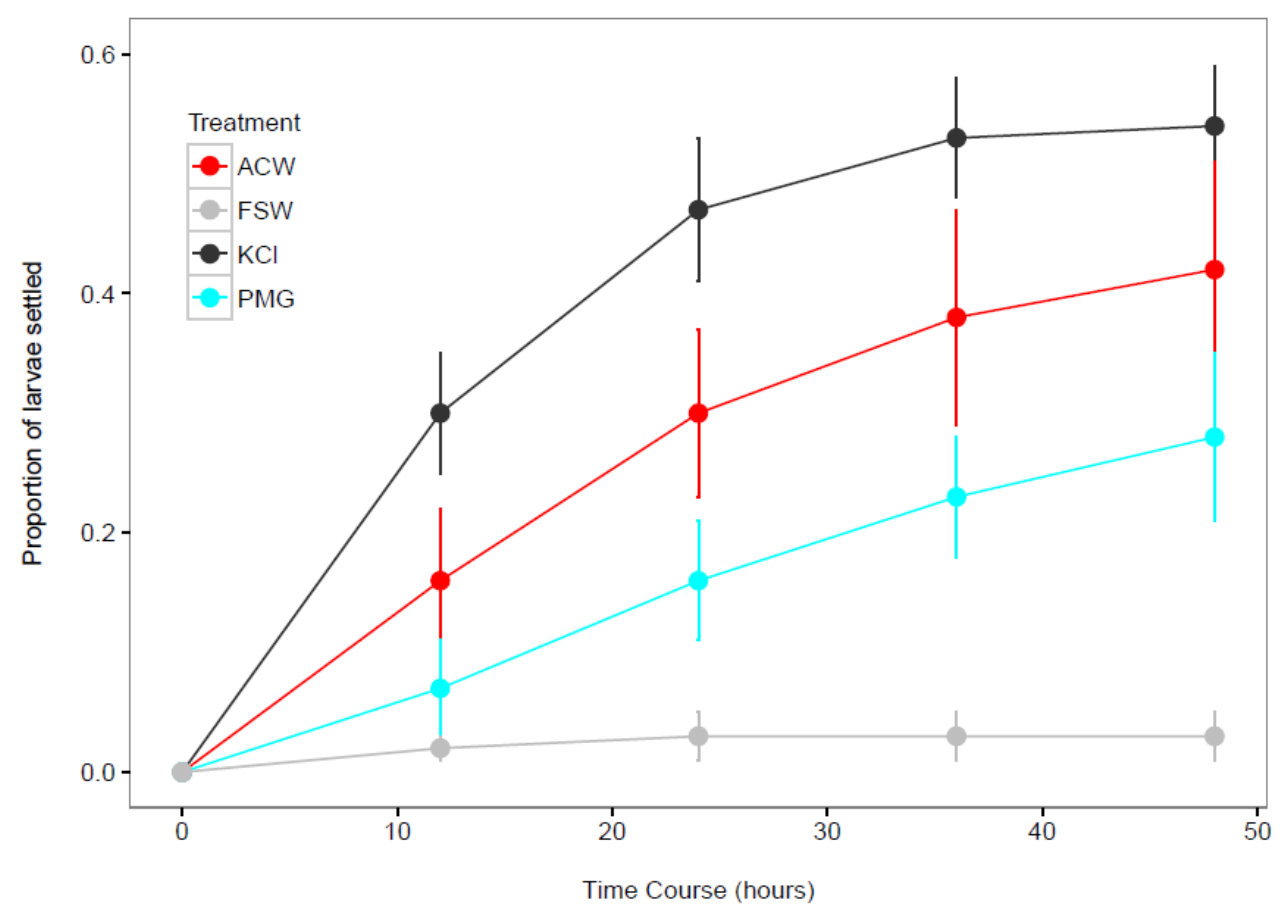

524

525 Figure 3: Settlement rates of larvae in response to different experimental factors. Time-

526 course data of larval settlement in adult-conditioned water (ACW; red line), filtered seawater

527 (FSW; grey line), potassium chloride (KCl; black line), and pedal mucus glasses (PMG; blue

528 line). Points represent running averages across all three experimental blocks; error bars represent

$5291 \mathrm{SE}$.

530 


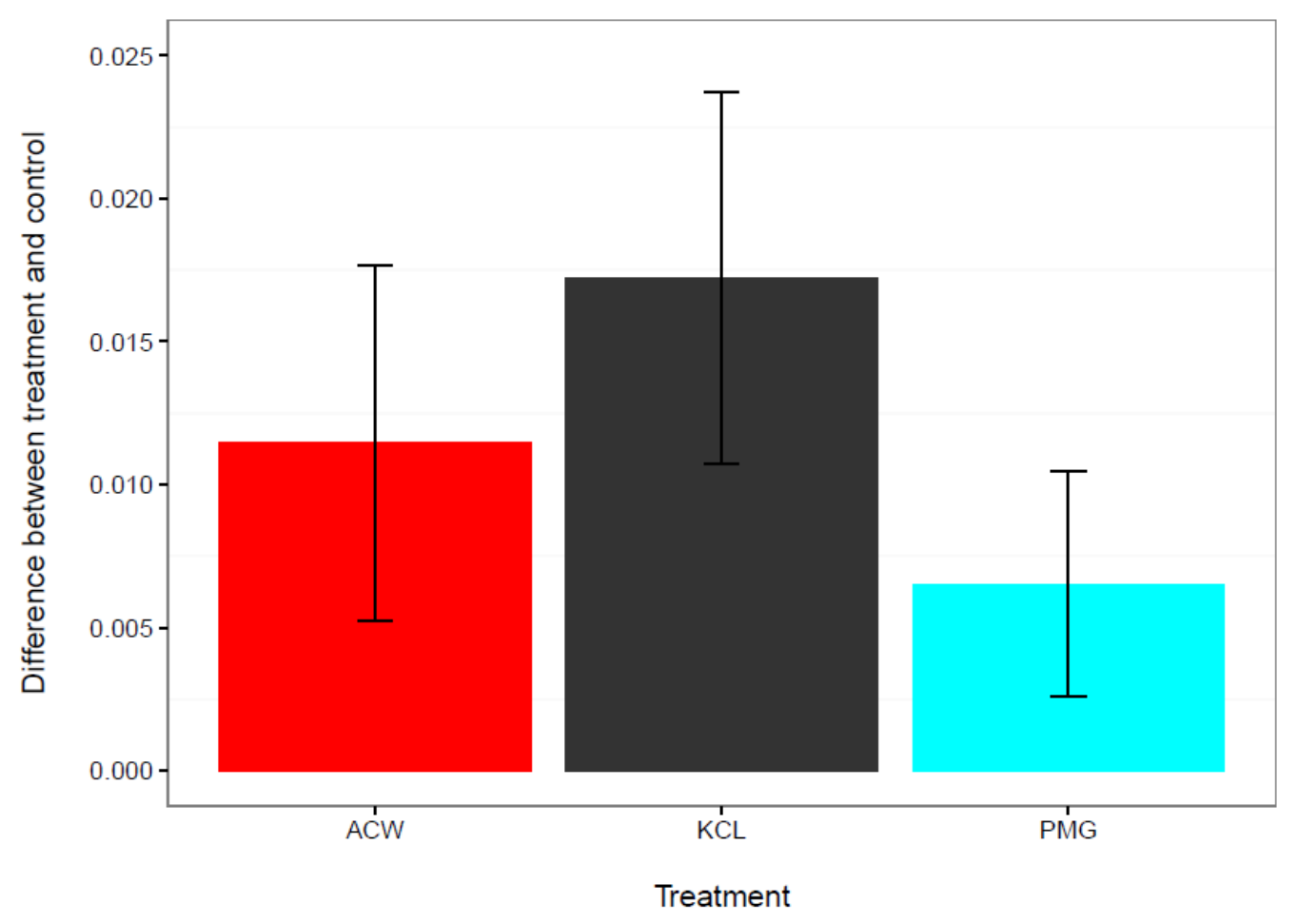

532 Figure 4: Comparisons of settlement factors to the control. The difference in settlement rate

533 ( $\lambda$, in units of $\ln$ (number larvae settled per hour)) between each settlement factor and the control

534 for adult-conditioned water (ACW; red), potassium chloride (KCl; grey), and pedal mucus

535 glasses (PMG; blue). Bar height represents the difference between each treatment mean and the

536 filtered seawater control, and error bars represent the $95 \%$ confidence intervals on those

537 differences. Error bars that do not overlap with zero indicate treatments with a significantly

538 higher settlement rate than the control at $\alpha=0.05$. 